\title{
De las tabernas a los sistemas rotativos de contratación: obreros, capataces y alcohol en las faenas portuarias (Chile, 1914-1923)
}

\section{From the taverns to the rotative hiring systems: Workers, foremen and alcohol at dock work (Chile 1914-1923)}

Camilo Santibáñez Rebolledo' (D) https://orcid.org/0000-0003-2936-3342

${ }^{1}$ Instituto de Estudios Internacionales, Universidad Arturo Prat, Iquique, CHILE. Email: sntibaez@gmail.com

\section{Resumen}

Este artículo trata sobre las prácticas de contratación y los mecanismos de favoritismo y retribución entablados por capataces y obreros en algunos puertos chilenos durante las primeras décadas del siglo XX. Basada en evidencia tomada de la prensa y boletines empresariales del norte salitrero y la bahía de Concepción, la conclusión sostiene que dicho favoritismo se fundó en un mecanismo de retribución constituido principalmente por el consumo de alcohol que los obreros hacían en bares asociados con los capataces que nominaban las cuadrillas. El modo de contestación obrera a esta arbitrariedad fueron los sistemas rotativos para la repartición del trabajo que los mismos bregaron por instaurar y mantener durante 1918 y 1923: la "redondilla" y el "turno numerado".

Palabras clave: trabajo portuario, prácticas de contratación, sistemas rotativos para la repartición del trabajo, capataces, alcohol.

\begin{abstract}
This paper is about the hiring practices and mechanisms of favoritism and retribution waged by foremen and workers in some Chilean docks during the first decades of the 20th century. Based on press and business bulletins from the docks of saltpeter and the Concepción area, the conclusion argues that this favoritism was based on a mechanism of retribution constituted mainly by the consumption of alcohol that the workers made in taverns associated with the foremen who nominated the crews. The workers' way of answering this arbitrariness were the rotating systems for the distribution of the work that they struggled to establish and keep during 1918 and 1923: the "redondilla" and the "turno numerado".
\end{abstract}

Keywords: dock work, hiring practices, rotative systems for the distribution of work, foremen, alcohol.

Recibido: 27 junio 2019. Aceptado: 2 diciembre 2019 
Durante las postrimerías del siglo XIX y las primeras décadas del siguiente, la contratación de la fuerza de trabajo para las faenas portuarias exhibió severas tensiones en los barcos, muelles y bodegas que sostenían el tráfico marítimo mundial (Chisholm, 2000; Weinhauer, 2000). En el caso chileno, la transición de la "configuración monopolística" a la "post-eventual" estuvo cimentada por una conflictiva "experiencia de la eventualidad", cuya principal tensión radicó en la autoridad que contratistas y capataces se arrogaron sobre la nominación de los hombres que componían las cuadrillas y los esfuerzos que estos últimos protagonizaron para recobrar dicha prerrogativa gremial, oponiendo el carácter equitativo de la tradición ocupacional decimonónica al favoritismo de los mencionados agentes intermediarios (Van Voss y Van der Linden, 2000; Santibáńez, 2017). Con la excepción de algunas referencias tangenciales, sin embargo, el funcionamiento del mecanismo de retribución que suponía este favoritismo ha permanecido historiográficamente inexplorado (Santibáñez, 2015a), tornándose una suerte de eslabón faltante en el estudio del proceso de trabajo portuario del período.

Este objeto de estudio está encuadrado por una serie de textos recientes que han permitido acotarlo, referidos a aspectos consustanciales del mismo contingente laboral en los albores del siglo XX. A saber: la compleja comunidad obrera que constituían, su propensión a la huelga y la relación que mantuvieron con el sindicalismo militante (Santibáńez, 2019, 2017 y 2018). Los mecanismos que mantuvieron los muelles operativos hasta la instauración de los sistemas rotativos, sin embargo, seguían siendo un asunto pendiente de revisión. Por esto el período de indagación obedece a las primeras constataciones de prácticas arbitrarias por parte de los capataces, en 1914, y se prolonga hasta el cierre del primer ciclo de conflictos por dichos sistemas rotativos, en 1923.

En suma, y con base en las quejas, reivindicaciones y conquistas obreras observadas en algunas faenas portuarias del norte salitrero y la bahía de Concepción durante la década mencionada, este artículo trata de resolver al menos parcialmente la insuficiencia en cuestión. Como hipótesis propone que, en estos puertos, dicho mecanismo se basó principalmente en el consumo de alcohol que los trabajadores hacían en bares asociados a los capataces, a cambio de que estos les proporcionaran un lugar permanente en las cuadrillas. La implementación de los sistemas rotativos en los mismos puertos entre 1918 y 1920, se argumenta finalmente, fue la respuesta de los obreros no favorecidos por el mecanismo descrito.

Aunque el propósito último de este artículo es contribuir en la dilucidación de las prácticas de los agentes intermediarios surgidos tras la derogación de los gremios estatales, el escrito también espera proveer antecedentes para el estudio de los mecanismos de contratación con anterioridad a su legislación nacional (Yáñez, 2008), e igualmente sobre el rol de los sindicatos en el control obrero del mercado de trabajo. Cuestiones, ambas, en las que el involucramiento del alcohol en circunstancias de contratación signadas por la eventualidad es, en efecto, propicia.

Para ello, el primer apartado esboza someramente el estado de la historiografía nacional y resume algunos de los principales avances ofrecidos por la historiografía extranjera respecto del rol laboral de estas bebidas en las relaciones laborales portuarias. El apartado siguiente presenta la evidencia conseguida para sustentar la hipótesis antes propuesta, relacionando los mecanismos de favoritismo y retribución entre capataces y obreros con el surgimiento de los sistemas de repartición rotativa, cuya instauración y defensa marcó las relaciones laborales en los muelles salitreros y la bahía penquista entre 1918 y 1923. 
En consecuencia, el grueso de la evidencia documental fue obtenido de los registros periodísticos de las mencionadas quejas, reivindicaciones y conquistas obreras, e igualmente de los reglamentos y notas gubernamentales que atestiguaron los períodos más álgidos de agitación laboral por esta causa. Específicamente, la prensa obrera y no obrera de Iquique, Antofagasta y Talcahuano, el Boletín de la Asociación de Productores de Salitre e informes emanados por las Intendencias de Tarapacá y Concepción.

\section{Trabajo y alcohol}

En décadas recientes, la historiografía chilena ha denotado la función transgresiva que el alcohol ejerció en las relaciones laborales durante los siglos XIX y XX. En general, los problemas de sujeción, ausentismo y productividad atribuidos a la ingesta de bebidas embriagantes, tanto como el papel que se le adjudicó en los informes de revueltas y motines en los lugares de trabajo, permitieron referir el consumo de alcohol como motivo del disciplinamiento laboral concomitante al proceso de proletarización (Illanes, 1990; Pinto Rodríguez, 1991; Grez, 2000; Godoy Orellana, 2003, 2016; Fernández Labbé et al., 2008). ${ }^{1}$

Al respecto, el estudio de Jorge Muñoz Sougarret (2008) sobre el alcohol como forma de pago de salario en la frontera sur de la Araucanía durante la segunda mitad del siglo XIX tomó una dirección diferente. Según propuso, los trabajadores no se hallaban totalmente despojados de los medios de producción en esta región y período, imposibilitando la formación de un mercado de trabajo asalariado y gestando en cambio "un proceso de explotación de las regalías posibles que tales trabajadores [podían] extraer de los terrenos por ellos cultivados" (Muñoz Sougarret, 2008, p. 57). En un contexto inflacionario constante, agregó, los trabajadores habrían aceptado "recibir los dividendos de su trabajo en bienes no devaluables que, además, eran constituyentes de su canasta familiar, [porque] dentro de un mercado de intercambios en que la moneda de curso forzoso era escasa, podían no solo ser traficados de manera conveniente sino, también, generar parámetros de medida para el resto de los productos" (Muñoz Sougarret, 2008, p. 39).

La singularidad de este estudio radica menos en el desvelamiento de la forma de pago que en el contrapunto al carácter transgresivo tradicionalmente asignado a la relación alcohol-trabajo. Pues el pago en bebidas alcohólicas fue también rastreado en la decadencia de la minería atacameña a mediados del mismo siglo (Venegas, 2008) e igualmente como signo del fracaso sufrido por los intentos de prohibición entre la fuerza de trabajo campesina (Herrera, 2008).

A diferencia de estos sectores, la incidencia laboral del alcohol no ha sido motivo de examen en los puertos chilenos. Esto, pese a la recurrente representación de fines del siglo XIX que caracterizó a los obreros portuarios como borrachos que "siempre llevaban sus puñales o revólveres para cuando les daba la gana [descargarlos] sobre cualquiera”, ${ }^{2} \mathrm{o}$ a los relatos contemporáneos de los cargadores nortinos sobre sus colegas, "que no tenían más que lo puesto, careciendo de un hogar, de un lecho donde descansar y por abrigo a la intemperie el fondo de los cachuchos dados vuelta en la playa", pero que eran siempre favorecidos por los capataces debido a que "el

1 Aunque no se centra en el ámbito laboral, cabe agregar el valioso estudio de Marcos Fernández Labbé sobre "Los usos de la taberna" en Chile durante el período 1870-1930 (2006). Particularmente en lo concerniente al rol local de los taberneros y el comportamiento de los trabajadores en las contiendas políticas electorales.

2 La cuestión social debe ser basada en la moral. La Chispa, segunda quincena de marzo de 1921. 
fruto íntegro del trabajo lo consumían en la cantina”, mientras el cargador que no bebía era despreciado por ser "un chancho que no da manteca". ${ }^{3}$

La historiografía trasnacional sugiere que esta cuestión no era anodina. En primer término, dicha historiografía ha cuestionado la percepción del alcohol como un elemento intrínsecamente constitutivo de la cultura obrera portuaria a partir de los matices contextuales y geográficos que contradicen dicha generalización (De Vries, 2000a, 2000b). Parte de estos matices se han basado en las medidas restrictivas que los propios obreros ejercieron o secundaron contra su consumo, de modo coincidente con las preocupaciones gerenciales por la eficiencia laboral (Mars, 1987; Pred, 1990; Trice, 1993). En Gotemburgo, por referir un caso bastante estudiado, fueron los propios sindicatos de estibadores los que impusieron medidas disciplinarias para impedir la ingesta de alcohol en los trabajadores eventuales (Andersen, 1992).

Sin embargo, esta historiografía ha documentado también toda una serie de variantes sobre el rol laboral del alcohol allí donde este efectivamente lo cumplió. En los muelles de Londres, por ejemplo, los bares fueron lugares comunes de contratación y pago de jornales, promoviendo que los obreros invitaran a beber a los capataces con la esperanza de ser nominados para el trabajo el día siguiente (Mankelow, 2000). En Le Havre hacia mediados del siglo XIX, los contratistas pagaban el jornal con fichas (tokens) a las cuadrillas, pues solo recibían el pago al concluir el trabajo concertado. Los hombres de estas cuadrillas podían canjear las fichas en determinados bares, siempre que compraran un trago en el establecimiento, y al concluir la totalidad del trabajo acordado el contratista volvía a comprarles las fichas a los dueños de los bares (Barzman, 2000). En las costas estadounidenses, en tanto, las prácticas que recurrían al alcohol convivieron con otras formas de extorsión relativas a la contratación (Cherny, 2000). Hasta mediados del siglo XX en los muelles neoyorquinos, estas cohabitaron con el soborno, el cohecho, el franqueo de préstamos, la usura crediticia, los rellenos falsos de nóminas y las contribuciones forzadas en beneficio de trabajadores accidentados o enfermos (Kimeldorf, 1988; Davis, C. J., 1998 y 2000; Cooke Johnson, 2000; Davis, S., 2000; Nelson, 2000).

En lo que concierne al caso chileno, en suma, lo que este resumen de variantes denota es la necesidad de examinar los mecanismos de contratación a partir de los cuales el alcohol habría sido involucrado específicamente.

\section{Capataces, contratación y alcohol en los puertos chilenos}

Hasta su conflictiva derogación nacional, en 1890, las labores portuarias chilenas fueron desempeñadas por gremios organizados y administrados por el Estado (Yávar, 1989; Pinto Vallejos, 1990, 1994; Grez, 2007). Aunque los antecedentes corresponden mayormente al norte salitrero, todo indica que fue solo con posterioridad a la disolución de tales gremios que la contratación quedó en manos de contratistas -en ocasiones denominados stevedores-, pues estos acudieron a determinados obreros para formar y proveer cuadrillas a las empresas involucradas en el tráfico marítimo, quienes se convirtieron, mediante esta labor de reclutamiento, en capataces de los contratistas. ${ }^{4}$

3 ¿Por qué se organizan los cargadores? El Proletario, 17 de enero de 1917.

4 ¿Por qué se organizan los cargadores? El Proletario, 20 de enero de 1917; Lo que desempeña un intermediario en las faenas marítimas. El Socialista, 12 de octubre de 1921. 
Debido a que la cantidad de hombres ocupados estaba definida por la cantidad de trabajo requerido, y que la nominación de los individuos que componían tales cuadrillas era atribución de estos capataces, la frecuencia de nominación en las cuadrillas resultó tan decisiva para los salarios de los primeros como fuente de poder para los segundos.

Esta tensión definió la fisonomía de las relaciones laborales de modo permanente. Pese a su escasez, las fuentes sugieren que "La Protectora de Trabajadores", el trust que los capataces organizaron a fines del siglo XIX en Iquique para expedir las "tarjetas" que habilitaban a los hombres para ocuparse en las faenas de embarque, se formó en disputa con los esfuerzos obreros por recobrar el monopolio de la contratación, evidenciados en la formación del "Gremio Libre de Jornaleros", en 1890, y la "Sociedad Gran Unión Marítima” en 1893 (Pinto Vallejos, 1994).5 En los albores del siglo siguiente, la Mancomunal del también puerto salitrero de Antofagasta protagonizó la misma disputa con el trust de contratistas locales (Parker, Valenzuela y Ávalos, 1985, p. 46; Mercado, 2004, p. 11).

Fuera de la región salitrera las tensiones parecen haber sido bastante semejantes. En 1903, por ejemplo, los estibadores de Valparaíso solicitaron "nombrar ellos [a los] capataces [e instaurar una] oficina recontroladora, que escoja o designe la jente" (Holley, 1905), y persistieron en 1917 a través de la solicitud para "la instalación de una Oficina del Trabajo [que se hiciera] cargo del nombramiento de las cuadrillas de las faenas marítimas" (Parker et al., 1985). Hacia 1920 en Talcahuano, un conflicto que comenzó como la disputa entre dos Consejos de obreros por arrogarse el monopolio del trabajo concluyó develando los intereses de los comerciantes locales por quebrar dicha prerrogativa mediante la asignación de capataces. Estos últimos, cabe señalar, habían formado uno de los dos Consejos referidos reclutando hombres en el vecino puerto de San Vicente y contaban con el respaldo de las autoridades marítimas locales. ${ }^{6}$

Por tanto, que los capataces lograran conservar las riendas de la nominación para las faenas hasta la segunda década del siglo XX, no es algo que deba darse por sentado. Por el contrario, dichos hombres debieron entablar mecanismos para reproducir y afianzar su dominio.

Según defiende la hipótesis, y los subtítulos siguientes tratarán de documentar, tales mecanismos se materializaron en una retribución exigida a los obreros por el favoritismo de ser recurrentemente nominados. Lo que se consumó en la ingesta de alcohol que los primeros hacían en determinadas tabernas asociadas a dichos capataces. Formándose, de este modo, cuadrillas de hombres fijos y fidelizados, que eran complementadas por otros obreros solo cuando la cantidad de trabajo lo requería.

Aunque corresponden al período en que los sistemas rotativos ya estaban en funcionamiento es decir, cuando los obreros previamente favorecidos y no favorecidos compartían las cuadrillas de trabajo-, es relevante pesquisar las tensiones que lo anterior parece haber generado entre los trabajadores. Por ejemplo, en Iquique durante 1920 -tras la instauración de la redondilla- un jornalero de la Casa Campbell solicitó el porte de armas reclamando "[amenazas de] ciertos individuos de malos antecedentes que por desgracia [trabajaban] también como jornaleros

5 ¿Por qué se organizan los cargadores? El Proletario, 20 de enero de 1917.

6 Los Trabajadores Marítimos son obligados a declarar la huelga. jAdelante!, 23 de diciembre de 1920; La huelga de los obreros marítimos continúa inquebrantable. jAdelante!, 24 de diciembre de 1920; La huelga de los compañeros Marítimos. jAdelante!, 28 de diciembre de 1920; La huelga marítima continúa en estatuquo. ;Adelante!, 29 de diciembre de 1920; La huelga de los marítimos toma caracteres bastante graves. ¡Adelante!, 30 de diciembre de 1920; La comedia toca a su término. ;Adelante!, 12 de febrero de 1921. 
en la bahía de este puerto". Tratándose -según la policía- de un obrero que contaba con "recomendaciones especiales, por no haber infrinjido los reglamentos de matrícula de jente de mar", el permiso fue concedido. El mismo año, un jornalero de la Nitrate Agencies que se identificó como "persona seria y trabajadora, muy conocida de las autoridades marítimas y de [sus] patrones [por jamás infringir los reglamentos]" realizó idéntica solicitud, basándose en los mismos argumentos. ${ }^{7}$ Como es de suponer, las huelgas exacerbaron estas rencillas. Quienes adherían llamaban "soplones de los capataces" a quienes no y, en ocasiones, como prueban los tres obreros muertos, más los heridos a cuchillo y a bala que dejó la huelga de 1923 en el mismo puerto, la situación podía cobrar ribetes dramáticos. ${ }^{8}$

Los sistemas rotativos aludidos, instaurados con diferentes nombres en Talcahuano, Antofagasta e Iquique durante 1918, 1919 y 1920, respectivamente, fueron esfuerzos en apariencia no concertados, pero que obedecían a un problema común: la arbitrariedad de los capataces en el nombramiento de los hombres que conformaban las cuadrillas.

Aunque la primera huelga por este motivo había estallado en los puertos salitreros durante 1916 -donde la extorsión mediante el consumo de alcohol ya era denunciada-, la relevancia del control sobre la contratación implicó conflictos laborales verdaderamente álgidos entre 1921 y 1923. Principalmente porque, según interpretaban los patrones, ello confería un poder inusitado a los gremios obreros y a los agitadores que los dirigían (Santibáńez, 2015b, 2017). Lo relevante de retener, no obstante, es que la instauración de estos sistemas rotativos -y posteriormente su defensa por parte de los trabajadores- puso en evidencia los vicios en que incurrían los capataces. No solo en el norte del país, sino también en la bahía penquista, cuestión que incluso los agentes estatales reconocían.

El primer subtítulo a continuación enfoca toda esta situación en los puertos del norte y el segundo en la bahía de Talcahuano (Figura 1).

\section{Los puertos del norte (1914-1923)}

Tal como se indicó, la huelga de 1923 en Iquique cerró un ciclo de conflictos por el control de la contratación, cuyo inicio había tenido lugar en el mismo puerto durante la segunda mitad de la década previa (Santibáńez, 2019). Tratando de evitar la derogación de la "redondilla" como resultado de un desenlace desfavorable, la prensa obrera de este puerto recordó las razones que habían forzado su instauración como sistema equitativo para la repartición del trabajo hacia 1920, describiendo a los capataces como "los más grandes sinvergüenzas que los trabajadores han tenido la desgracia de soportar en los trabajos de la bahía”, y recordando que estos "anteriormente urgían a los obreros, haciéndoles [gastar] en alcohol la miserable paga que recibían, pues algunos de ellos regentaban prostíbulos, cantinas de bebidas y garitos", ${ }^{9}$ donde "por razón de su trabajo [los obreros] se veían en la obligación de consumir [...] la mayor parte

7 Archivo de la Intendencia de Tarapacá. Vol. 1174, Decretos de la Intendencia, 1920, legajo 5.

8 Cómete las peras. El Productor, 15 de agosto de 1922; ¿Quién es el responsable? y De la huelga. El Sembrador, 3 y 24 de noviembre de 1923, respectivamente; Nuevamente los atentados, La cuestión marítima, Situación que debe terminar y Los de la IWW siguen asaltando. El Nacional, 2, 12, 22 y 28 de noviembre de 1923, respectivamente; Infamias que está cometiendo la Policía de orden de la Prefectura. El Despertar de los Trabajadores, 28 de noviembre de 1923.

9 La huelga de los obreros marítimos en el puerto. El Despertar de los Trabajadores, 28 de septiembre de 1923. 


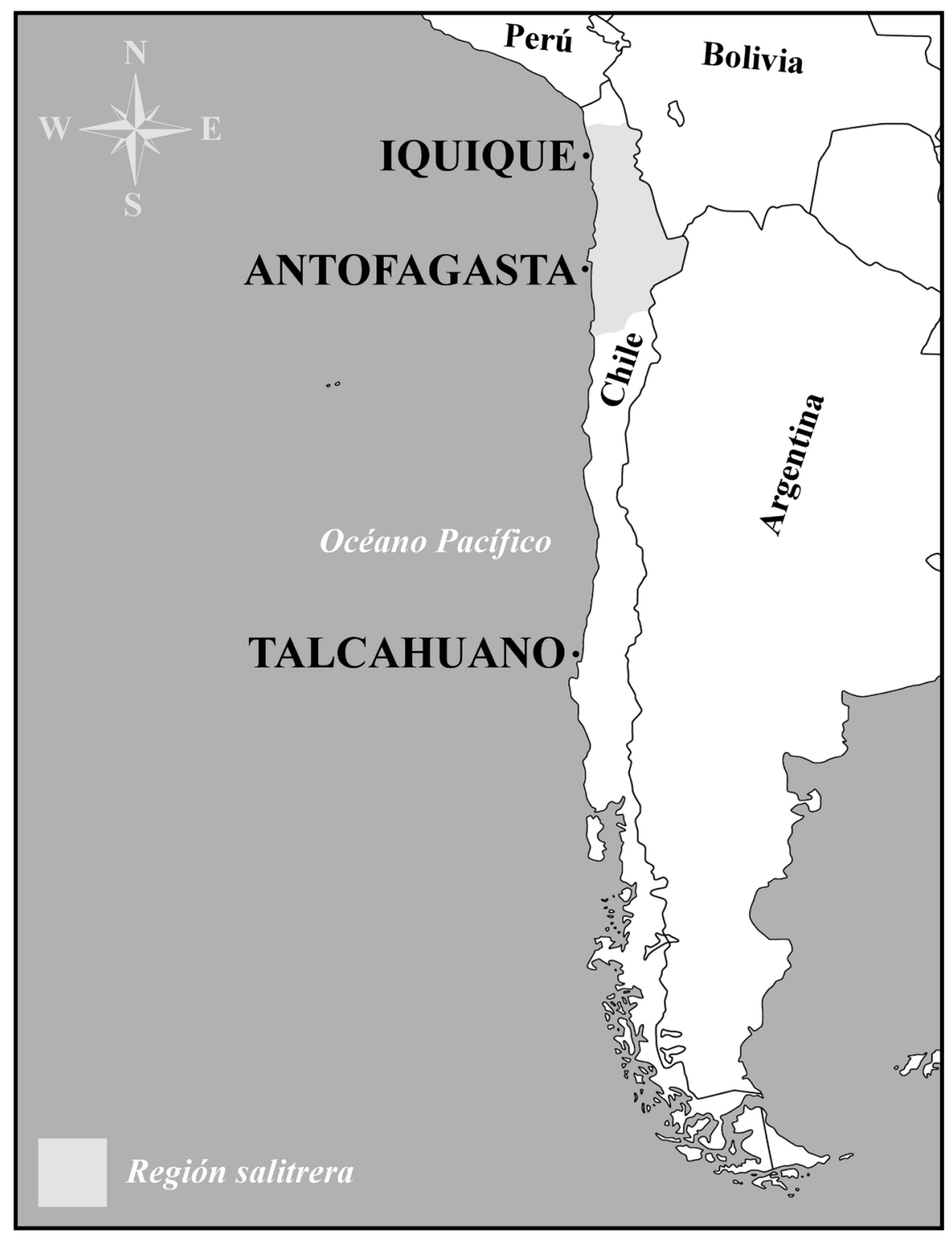

Figura 1. Mapa indicando la ubicación de los puertos de Iquique, Antofagasta y Talcahuano en la costa chilena. El territorio ensombrecido seńala la región salitrera.

de su salario". ${ }^{10}$ El logro de la redondilla había sido precisamente quebrar esta dependencia extorsiva. "Ya no son cuadrillas privilegiadas las que trabajan", escribieron los obreros en 1923, "ya no disponen los capataces de gente sumisa para verificar sus negocios particulares". ${ }^{11}$

La revisión de las reivindicaciones que empujaron a los jornaleros y estibadores de Iquique a la huelga en 1916 -secundados por los obreros de Caleta Buena, Junín y Pisagua- otorga razón a dichos alegatos. Según el informe que redactó la comisión gubernamental enviada en defensa de los intereses fiscales comprometidos, los capataces al alero del contratista "pagaban los

10 El movimiento huelguista sigue firme. El Despertar de los Trabajadores, 2 de octubre de 1923.

11 El conflicto de Iquique. El Despertar de los Trabajadores, 6 de enero de 1923. 
jornales en las cantinas o garitos, dando ocupación tan sólo a los que dejaban en estos locales su dinero o a los que lo gastaban en un burdel que pertenece a un pariente de uno de los capataces" (Oyarzún, Concha y Philippi, 1917). Como develan las acusaciones contra el capataz de lanchas de la casa Nitrate Agencies, este mecanismo reproducía "un circuito de protejidos [sic], [que es preferido] todo el tiempo en las nombradas". ${ }^{12}$ La comisión gubernamental, de hecho, propuso que la nominación de las cuadrillas fuera atribución de la Gobernación Marítima, que los pagos se efectuaran en su edificio y que el cargo de capataz fuera incompatible con la tenencia de cantinas o semejantes (Santibáńez, 2015b). Mientras que la primera de estas recomendaciones tuvo que adaptarse a las presiones del contratista local-quien vetó a todos los hombres que consideró problemáticos-, la segunda parece haber sido recogida en la nueva reglamentación dispuesta para toda la costa salitrera. ${ }^{13}$

La tercera medida, en tanto, parece haber sido una condición ya dictaminada que no se respetaba. En las acusaciones que hicieron los cargadores de la bodega El Morro en Iquique durante 1914, por ejemplo, estos señalan expresamente que "el capataz [...] posee un negocio de licores apesar [sic] de estarles prohibido a los capataces de cuadrilla mantener esta clase de negocios". ${ }^{14}$ En la bodega Lagunas del mismo puerto, por referir un segundo caso, los cargadores habían denunciado unas semanas antes que el capataz hostigaba "a aquellos que no se muestran dispuestos a dejar el total o parte de lo que ganen en una cantina de su propiedad llamada Bar Obrero", ${ }^{15}$ cuestión que estos últimos trataron de contrarrestar forzando el nombramiento de "un segundo capataz", pero obrero y con roles fiscalizadores. ${ }^{16}$

La insistencia de 1916, como se indicó, tampoco pudo desterrar del todo la práctica. En 1917 los cargadores señalaban que la "obligación de la botella" seguía imponiéndose en las bodegas iquiqueńas, donde los capataces velaban por "la propagación de esta costumbre". Incorporando un elemento al mecanismo recurrente; de hecho, estos obreros describieron la retribución del siguiente modo: "Ellos rejentan [sic] sus cantinas, los vales que ellos espiden [sic] son canjeados con puntualidad ¿y quién [sic] no lo haga? será hostilizado por los chupas de estos verdugos". ${ }^{17}$

Pese a que el caso de Antofagasta carece de documentación suficiente para proferir aseveraciones, hay algunos indicios que avalan conjeturas en la misma línea. En 1919, por ejemplo, bajo la amenaza de una paralización general de la bahía, la naciente Federación Obrera Marítima de

12 Un capataz de lanchas que se hace célebre por sus tropelías contra los lancheros. El Proletario, 11 de marzo de 1916.

13 De Pisagua. El Surco, 15 de septiembre de 1918. Como constata el intento gubernamental por instaurar la obligatoriedad del retrato en las matrículas que autorizaban a los hombres para laborar en las faenas portuarias, en 1917, la intervención estatal sobre las relaciones laborales de este sector, y en particular sobre la fuerza de trabajo, estuvo lejos de ser excepcional. Por el contrario, fue un lugar de atención permanente para las autoridades, en resguardo, seguramente, de la vulnerabilidad bajo la que pendían los intereses fiscales.

14 En la bodega del Morro de los señores Gildemeister i Cía. El Proletario, 25 de julio de 1914.

15 Situación intolerable. El Proletario, 3 de enero de 1914.

16 Solución del conflicto. El Proletario, 25 de enero de 1914.

17 ¿Por qué se organizan los cargadores? El Proletario, 3 de enero de 1917. Para 1918 la incompatibilidad figura infringida en otras partes de la región nortina. En el puerto de Arica, por ejemplo, los obreros fueron a la huelga porque el capataz los obligaba a cobrar los jornales en la taberna de su propiedad, tarde por las noches. En Junín el listado de abusos que los cargadores adjudicaron a su capataz menciona que este mantenía una cantina en la misma caleta. Respectivamente: Los trabajadores de Arica. El Despertar de los Trabajadores, 24 de septiembre de 1918. De Pisagua. El Surco, 15 de septiembre de 1918. 
Antofagasta forzó al municipio a "retirar todos los burdeles que [expedían] bebidas alcohólicas cerca de las faenas marítimas". ${ }^{18}$ Aunque la nota no hace ligazón expresa con los capataces, la conquista tuvo lugar tras dos paralizaciones el mismo ańo: la primera contra las coimas que estos cobraban a los jornaleros que nombraban, y la segunda -secundada por los lancheros, estibadores, cargadores y movilizadores de la bahía- por la instauración del "turno rotativo"; el que finalmente lograron en medio de la severa escasez de trabajo provocada por la crisis de la industria del nitrato. ${ }^{19}$ "Los capataces no intervienen en la designación de estos turnos", signó el documento gubernamental resolutivo, "sólo dirijen [sic] la faena a bordo, se reciben de las cuadrillas nombradas y representan los intereses del patrón”. ${ }^{20}$

En efecto, la implementación de este "turno rotativo" en Antofagasta, en 1919, y el de la redondilla en Iquique durante el año siguiente tienen por patrón común las arbitrariedades cometidas por los capataces. La relación del consumo de alcohol con estas arbitrariedades está mejor documentada en el segundo caso que en el primero, pero la extremación de recursos por parte de los obreros de Antofagasta con el objeto de remover los expendios de alcohol es sugerente y difícil de explicar de otra forma.

\section{La bahía de Concepción}

Alrededor de 1918, también los estibadores de Talcahuano habían conseguido instaurar un sistema rotativo de repartición del trabajo que denominaban como "turno numerado". Según señalaron los propios obreros, el carácter equitativo de este sistema obedecía a la necesidad de contrarrestar las arbitrariedades cometidas por patrones y capataces, quienes "llevaban a trabajar a aquellos individuos que les conviniera, en beneficio de sus insaciables faltriqueras". Al igual que en las descripciones nortinas, los trabajadores penquistas precisaron que "solamente tenían derecho a trabajar los individuos que fueran buenos bebedores, los que poseyeran fuerzas brutales y los mansos que no protestaban jamás de aquel terrible oprobio". ${ }^{21}$

La intervención que hizo el diputado del ala izquierda del Partido Demócrata y otrora estibador Juan Pradenas en la Cámara, a fines de 1921, es coincidente con tales reclamos. Según manifestó, refiriéndose al período previo a 1918, "los capataces que embarcaban obreros para las faenas de carga o descarga, elejían [sic] sólo a los obreros que consumían bastante alcohol, a los más borrachos, a los que más derrochaban, para que dejaran en sus tabernas todo su jornal, el pan de sus familias". Gracias al "turno numerado", agregó, los obreros habían revertido su condición "harapienta y famélica", pues "no [derrochaban] ya el dinero en el vicio nefasto del alcohol por imposiciones superiores". ${ }^{22}$

El Informe que preparó el Intendente de Concepción en 1921, en tanto, también reconoció que el turno numerado o redondilla cumplía con "[impedir] los abusos de los capataces". En concreto, "que, manteniendo el derecho o facultad de elegir la gente de cada faena [podían]

18 De Antofagasta. El Surco, 21 de noviembre de 1919.

19 El conflicto de los jornaleros y la casa Stevenson y Cómo se abusa. El Socialista, 14 de junio de 1919; Conflicto solucionado. El Socialista, 4 de septiembre de 1919; Del Gremio de Jornaleros de Mar. El Socialista, 8 de septiembre de 1919; La huelga general se declaró ayer en la bahía y Los jornaleros de mar son obligados a la huelga por la torpe conducta del Gobernador Marítimo. El Socialista, 18 de septiembre de 1919; La huelga de los jornaleros. El Socialista, 19 y 20 de septiembre de 1919.

20 Nuestros grandes triunfos. El Socialista, 25 de septiembre de 1919.

21 Capítulos de nuestra historia.;Adelante!, 23 de marzo de 1921.

22 En la Cámara de Diputados. ;Adelante!, 17 de noviembre de 1921. 
exigir retribuciones indebidas, como ser una cuota de salario o el compromiso de comprarles licores o menestras en sus negocios" (Acevedo, 1923).

Según la documentación, el consumo de alcohol efectivamente parece haber sido el mecanismo habitual para granjearse un turno en las diferentes faenas portuarias de la bahía, incluyendo las bodegas. Por ejemplo, en 1917, los obreros de El Morro se quejaban porque los capataces bodegueros "[procedían] arbitrariamente con [los] trabajadores": "El hombre sobrio, que [bebía] poco, [duraba] sólo una o dos semanas en la bodega", aseguraban. "En cambio el que [derrochaba] su dinero en alcohol que les [brindaban] los bodegueros, esos sí que [tenían] trabajo permanente". ${ }^{23}$ Según denunciaron los obreros de la Casa Gibbs, el capataz tenía instalado el chinchel en la misma bodega. El de la Casa Grace, en tanto, "[expedía] vales para alcohol en negocios particulares, de los que recibía un porcentaje”. Quejas similares se registran en las bodegas de San Vicente durante 1920, donde los capataces tenían "boliches" sin patente amparados por la policía, en los que "alcoholizaban a los trabajadores y hostilizaban a los que no bebían tanto" (Santibáńez, 2018b). ${ }^{24}$

Considerando los antecedentes del apartado previo, por tanto, resulta evidente que, en las prácticas de contratación de las faenas portuarias en Talcahuano tanto como en Iquique, el consumo de alcohol tuvo un rol relevante a principios del siglo XX. Particularmente, como mecanismo de retribución por parte de los obreros recurrentemente nominados por los capataces, en bares asociados a estos últimos.

También puede notarse, en ambas regiones, la directa ligazón entre el surgimiento de los sistemas de turnos rotativos o numerados para la distribución del trabajo, y las prácticas de favoritismo ejercidas por los capataces. Específicamente, como método para contrarrestar las arbitrariedades en la nominación, rompiendo el referido mecanismo retributivo que constituía la base social de su rol como proveedores de fuerza de trabajo.

En consecuencia, lo mismo que había acontecido en 1918 en Talcahuano aconteció durante 1920 en Iquique y, según es dable suponer, en 1919 en Antofagasta. Los sistemas rotativos se habían implementado para desplazar a los capataces, dejando obsoletos los mecanismos de retribución basados en el alcohol.

\section{Conclusiones}

La variabilidad del trabajo portuario, pero particularmente el control que los capataces lograron arrogarse sobre su distribución en el tránsito del siglo XIX al XX definieron la tensión que marcó las relaciones laborales durante las dos décadas siguientes en las faenas de estiba chilenas. Esto es, la disputa por la nominación para la composición de las cuadrillas (Santibáńez, 2017).

Como evidenció el conflictivo proceso por la instauración y derogación de los sistemas rotativos entre 1918-1923, su carácter equitativo tuvo por objeto contrarrestar las arbitrariedades de dichos capataces en el nombramiento permanente de determinados hombres en desmedro de otros; siendo contratados - estos últimos- únicamente cuando los primeros no bastaban para la cantidad de fuerza de trabajo requerida.

23 La huelga marítima. jAdelante!, 28 de julio de 1917.

24 Una carta. ;Adelante!, 28 de julio de 1917. 
Hasta entonces, y en la medida en que dicho favoritismo efectivamente surtía de hombres permanentes a los contratistas intermediarios, el rol de los capataces había probado ser de toda utilidad para el tráfico marítimo y había reproducido su rol en la estructura de contratación. No obstante, esta posición también había facilitado que dichos capataces demandaran una retribución a los obreros favorecidos, materializada en el consumo de alcohol en bares de su propiedad o íntimamente ligados.

Advertido por los obreros no favorecidos de esta connivencia entre capataces, alcohol y contratación, pero reacio a involucrarse en lo relativo a la última, el gobierno chileno trató primero de desterrar el alcohol y solo luego aceptó la instauración de los turnos rotativos. Las medidas respecto del uso de los bares pueden rastrearse desde 1916 y los turnos rotativos hacia 1920; pero en 1923 la incompatibilidad entre el cargo de capataz -incluidos sus "deudos inmediatos"- $\mathrm{y}$ "el ejercicio de cualquier comercio o industria que tenga relación directa o indirecta con los individuos ocupados en las faenas" seguía requiriendo explicitación. ${ }^{25}$ Para entonces, si bien el sistema de turnos había logrado instalarse (Santibáńez, 2015a y 2019), ello había sido a costa de una severa conflictividad y -al menos en el norte- bajo la supeditación de un empleado contratado con este propósito por las casas embarcadoras. Según notificó confidencialmente el gobernador marítimo, esta tutelada concesión por parte de las firmas tenía el expreso propósito de "[evitar] que las nombradas [quedaran] al capricho de los capataces". ${ }^{26}$

Despojados de la nominación de las cuadrillas, y por tanto inutilizada la cantina como lugar de retribución obrera, la primera era dorada de los capataces había concluido en los muelles chilenos, quedando su función confinada a la mera dirección de las faenas. ${ }^{27} \mathrm{El}$ inmoderado consumo obrero de alcohol, cuya expansión provocaba un escozor semejante en burgueses, cristianos y socialistas (Fernández Labbé, 2008; Godoy Sepúlveda, 2008; Navarro, 2019), había hallado tope como recurso laboral en las faenas portuarias. Los "chanchos que no daban manteca" se habían impuesto como clase, modernizando los mecanismos de contratación y la venta de su fuerza de trabajo.

\section{Agradecimientos}

Este artículo fue originalmente presentado en la III European Labour History Network Conference celebrada en Ámsterdam los días 18 al 21 de septiembre de 2019 gracias al financiamiento de la Beca de Apoyo a la Investigación de la Vicerrectoría de Postgrado de la Universidad de Santiago de Chile.

25 Reglamento sobre redondilla. Boletín mensual Asociación de Productores de Salitre, 42. Tomo IV, pp. 544-546, 13 de junio de 1922; Diario Oficial. 13303, 13 de junio de 1922; y Duplicado rectificado. Ministerio de Marina, 311, 28 de abril de 1922.

26 Archivo de la Intendencia de Tarapacá. Vol. 1.203, Archivo Confidencial (1920-1923), legajos 124-127.

27 Reglamento sobre redondilla. Boletín mensual Asociación de Productores de Salitre, 42. Tomo IV, pp. 544-546, 13 de junio de 1922. 


\section{Referencias citadas}

Acevedo, A. (1923). El problema de las faenas maritimas en la zona salitrera. El sistema de redondilla y la nueva reglamentación. Talcahuano, Chile: Librería e Imprenta Moderna.

Andersen, S. A. (1992). Dockers' culture in three North European port cities: Hamburg, Gothenburg and Aarhus 1880-1960. En Holm, P. y Edwards, J. (Eds.). North Sea Ports and Harbours: Adaptations to Change (pp. 133-158). Esbjerg, Dinamarca: Fiskeri og Sofartsmuseet.

Barzman, J. (2000). Dock labour in Le Havre, 1790-1970. En Davies, S. et al. (Eds.). Dock Workers. International Explorations in Comparative Labour History, 1790-1970 (pp. 57-83). Aldershot, Inglaterra: Ashgate.

Cherny, R. W. (2000). Longshoremen of San Francisco Bay, 1849-1960. En Davies, S. et al. (Eds.). Dock Workers. International Explorations in Comparative Labour History, 1790-1970 (pp. 102-140). Aldershot, Inglaterra: Ashgate.

Chisholm, J. (2000). Waterfront conflict: dockers' strategies and collective actions. En Davies, S. et al. (Eds.). Dock Workers. International Explorations in Comparative Labour History, 1790-1970 (pp. 709-720). Aldershot, Inglaterra: Ashgate.

Cooke Johnson, L. (2000). Criminality on the docks. En Davies, S. et al. (Eds.). Dock Workers. International Explorations in Comparative Labour History, $1790-1970$ (pp. 721-745). Aldershot, Inglaterra: Ashgate.

Davis, C. J. (1998). 'All I got's a hook': New York longshoremen and the 1948 dock strike. En Winslow, C. (Ed.). Waterfront Workers: New Perspectives on Race and Class (pp.131-154). Urbana, IL: University of Illinois Press.

Davis, C. J. (2000). New York city and London, 1945-60. En Davies, S. et al. (Eds.). Dock Workers. International Explorations in Comparative Labour History, $1790-1970$ (pp. 213-230). Aldershot, Inglaterra: Ashgate.

Davis, S. (2000). Employers and dock labour: employment, work and industrial relations in international perspective. En Davies, S. et al. (Eds.). Dock Workers. International Explorations in Comparative Labour History, 1790-1970 (pp. 604-626). Aldershot, Inglaterra: Ashgate.

De Vries, D. (2000a). Construction of the image of dock labour. En Davies, S. et al. (Eds.). Dock Workers. International Explorations in Comparative Labour History, 1790-1970 (pp. 681-708). Aldershot, Inglaterra: Ashgate.

De Vries, D. (2000b). Nationalism and the making of dock labour in British-ruled Palestine. En Davies, S. et al. (Eds.). Dock Workers. International Explorations in Comparative Labour History, 1790-1970 (pp. 231-250). Aldershot, Inglaterra: Ashgate.

Fernández Labbé, M. (2006). Los usos de la taberna: Renta fiscal, combate al alcoholismo y cacicazgo político en Chile. 1870-1930. Historia, 39(2), 369-429.

Fernández Labbé, M. (2008). Las puntas de un mismo lazo. Discurso y representación social del bebedor inmoderado en Chile, 1870-1930. En Fernández Labbé, M. et al. (Eds.). Alcohol y trabajo. El alcohol y la formación de las identidades laborales. Chile, siglos XIX y XX (pp. 91-120). Osorno, Chile: Editorial Universidad de Los Lagos. 
Fernández Labbé, M., Godoy, E., Herrera, P., Muñoz, J., Venegas, H. y Yáńez, J. C. (Eds.). (2008). Alcohol $y$ trabajo. El alcohol y la formación de las identidades laborales. Chile, siglos XIX y XX. Osorno, Chile: Editorial Universidad de Los Lagos.

Godoy Orellana, M. (2003). Fiesta, borrachera y violencia entre los mineros del Norte chico (1840-1900). Revista de Historia Social y de las Mentalidades, 7, 81-117.

Godoy Orellana, M. (2016). Paternalismo industrial y disciplinamiento cultural en el mundo festivo de las ciudades carboníferas chilenas: Lota, 1920-1950. Atenea, 514, 31-48.

Godoy Sepúlveda, E. (2008). El discurso moral de los anarquistas chilenos en torno al alcohol a comienzos del siglo XX. En Fernández Labbé, M. et al. (Eds.). Alcohol y trabajo. El alcohol y la formación de las identidades laborales. Chile, siglos XIX y XX (pp. 121-144). Osorno, Chile: Editorial Universidad de Los Lagos.

Grez, S. (2000). Transición en las formas de lucha: Motines peonales y huelgas obreras en Chile (18911907). Historia, 33, 141-225.

Grez, S. (2007). De la "regeneración del pueblo" a la huelga general: Génesis y evolución histórica del movimiento popular en Chile (1810-1890). Santiago: RIL Editores.

Herrera, P. (2008). 'Trabajar para beber o beber para trabajar'. Campesinado, alcohol y relaciones sociolaborales en Chile, 1867-1910. En Fernández Labbé, M. et al. (Eds.). Alcoholy trabajo. El alcoholy la formación de las identidades laborales. Chile, siglos XIX y XX (pp. 63-90). Osorno, Chile: Editorial Universidad de Los Lagos.

Holley, H. (1905). Las Huelgas. Prueba para optar al grado de Licenciado, Facultad de Leyes y Ciencias Políticas, Universidad de Chile, Santiago.

Illanes, M. A. (1990). Azote, salario y ley. Disciplinamiento de la mano de obra en la minería de Atacama (1817-1850). Proposiciones, 19, 90-122.

Kimeldorf, H. (1988). Reds or Rackets? The Making of Radical and Conservative Unions on the Waterfront. California, CA: University of California Press.

Mankelow, R. (2000). The port of London, 1790-1970. En Davies, S. et al. (Eds.). Dock Workers. International Explorations in Comparative Labour History, 1790-1970 (pp. 365-385). Aldershot, Inglaterra: Ashgate.

Mars, G. (1987). Longshore drinking, economic security and union politics in Newfoundland. En Douglas, M. (Ed.). Constructive Drinking: Perspectives on Drink from Anthropology (pp. 91-101). Cambridge, MA: Cambridge University Press.

Mercado, J. (2004). Combinación Mancomunal de Obreros de Antofagasta y politización popular, 1903-1906. Anuario de Pregrado, Facultad de Filosofía y Humanidades, Universidad de Chile, Santiago.

Muñoz Sougarret, J. (2008). Notas sobre la relación entre alcohol y trabajo en la frontera sur de la Araucanía. Segunda mitad del siglo XIX. En Fernández Labbé, M. et al. (Eds.). Alcohol y trabajo. El alcohol $y$ la formación de las identidades laborales. Chile, siglos XIX y XX (pp. 37-62). Osorno, Chile: Editorial Universidad de Los Lagos.

Navarro, J. (2019). Fiesta, alcohol y entretenimiento popular. Crítica y prácticas festivas del Partido Obrero Socialista. Chile, 1912-1922. Historia, 52(1), en prensa. 
Nelson, B. (2000). Longshoremen in the port of New York, 1850-1940. En Davies, S. et al. (Eds.). Dock Workers. International Explorations in Comparative Labour History, 1790-1970 (pp. 386-404). Aldershot, Inglaterra: Ashgate.

Oyarzún, E., Concha, J. E. y Philippi, J. (1917). Informe presentado al Supremo Gobierno sobre las huelgas de Iquique en 1916. Santiago.

Parker, C., Valenzuela, S. y Ávalos, G. (1985). Perspectiva del desarrollo histórico de las organizaciones de los obreros maritimos chilenos. Memoria para optar al título de Profesor de Estado en Historia y Geografía, Universidad Católica de Valparaíso, Valparaíso.

Pinto Rodríguez, J. (1991). Tras la huella de los paraísos artificiales. Mineros y campesinos de Copiapó, 1700-1850. Proposiciones, 20, 232-247.

Pinto Vallejos, J. (1990). La transición laboral en el norte salitrero: La Provincia de Tarapacá y los orígenes del proletariado en Chile, 1870-1890. Historia, 25, 207-228.

Pinto Vallejos, J. (1994). En el camino de la mancomunal: Organizaciones obreras en la Provincia de Tarapacá, 1880-1895. Cuadernos de Historia, 14, 81-135.

Pred, A. (1990). Lost Words and Lost Worlds: Modernity and the Language of Everyday Life in Late NineteenthCentury Stockholm. Cambridge, Estados Unidos: Cambridge University Press.

Santibáñez Rebolledo, C. (2015a). Huelgas y lockouts portuarios por la redondilla: Los conflictos por el control de la contratación en los muelles chilenos (1916-1923). Tesis para optar al grado de Magíster en Historia, Mención Historia de Chile, Departamento de Historia, Universidad de Santiago de Chile, Santiago.

Santibáńez Rebolledo, C. (2015b). El movimiento obrero en los muelles salitreros chilenos: Apuntes en torno a un informe de huelgas (Iquique 1916). Páginas, 14, 7-19.

Santibáńez Rebolledo, C. (2017). Los trabajadores portuarios chilenos y la experiencia de la eventualidad: Los conflictos por la redondilla en los muelles salitreros (1916-1923). Historia, 50(2), 699-728.

Santibáńez Rebolledo, C. (2018a). La IWW y el movimiento obrero en Chile: El caso de los obreros portuarios nortinos (1919-1923). Diálogo Andino, 55, 19-28.

Santibáńez Rebolledo, C. (2018b). Los estibadores de Talcahuano y San Vicente en la prensa obrera local, 1893-1948. Informe preparado para el Comunal Talcahuano-San Vicente de la Unión Portuaria del Biobío, Talcahuano.

Santibáñez Rebolledo, C. (2019). Comunidades obreras portuarias y propensión a la huelga: Iquique, 1923. Avances del Cesor. Vol. XVI(21), 159-172.

Trice, H. M. (1993). Occupational Subculture in the Workplace. Ithaca, NY: ILR Press.

Van Voss, L. H. y Van der Linden, M. (2000). Dockers' configurations. En Davies, S. et al. (Eds.). Dock Workers. International Explorations in Comparative Labour History, 1790-1970 (pp. 762-780). Aldershot, Inglaterra: Ashgate.

Venegas, H. (2008). Trabajo y alcohol: una relación conflictiva. La experiencia minera de Atacama en el siglo XIX. En Fernández Labbé, M. et al. (Eds.). Alcohol y trabajo. El alcoholy la formación de las identidades laborales. Chile, siglos XIX y XX (pp. 9-36). Osorno, Chile: Editorial Universidad de Los Lagos. 
Weinhauer, K. (2000). Power and control on the waterfront: casual labour and decasualisation. En Davies, S. et al. (Eds.). Dock Workers. International Explorations in Comparative Labour History, 1790-1970 (pp. 580-603). Aldershot, Inglaterra: Ashgate.

Yáñez, J. C. (2008). La intervención social en Chile y el nacimiento de la sociedad salarial (1907-1932). Santiago: RIL Editores.

Yávar, A. (1989). El gremio de jornaleros y lancheros de Valparaíso, 1837-1859. Etapa de formación. Historia, 24, 319-395.

\section{Fuentes Periódicas Consultadas}

¡Adelante!, Talcahuano.

Boletín mensual Asociación de Productores de Salitre, Valparaíso.

El Despertar de los Trabajadores, Iquique

El Proletario, Iquique.

El Socialista, Antofagasta.

El Surco, Iquique.

La Chispa, Talcahuano. 